Hwee Teoh, Adrian Quan, K. W. Annie Bang, Guilin Wang, Fina Lovren, Vivian Vu, Jack J. Haitsma, Paul E. Szmitko, Mohammed Al-Omran, Chao-Hung Wang, Milan Gupta, Mark D. Peterson, Haibo Zhang, Lawrence Chan, John Freedman, Gary Sweeney and Subodh Verma

Am J Physiol Endocrinol Metab 295:658-664, 2008. First published Jul 15, 2008;

doi:10.1152/ajpendo.90384.2008

You might find this additional information useful...

Supplemental material for this article can be found at:

http://ajpendo.physiology.org/cgi/content/full/90384.2008/DC1

This article cites 45 articles, 25 of which you can access free at:

http://ajpendo.physiology.org/cgi/content/full/295/3/E658\#BIBL

Updated information and services including high-resolution figures, can be found at:

http://ajpendo.physiology.org/cgi/content/full/295/3/E658

Additional material and information about AJP - Endocrinology and Metabolism can be found at: http://www.the-aps.org/publications/ajpendo

This information is current as of January 20, 2009 . 


\title{
Adiponectin deficiency promotes endothelial activation and profoundly exacerbates sepsis-related mortality
}

\author{
Hwee Teoh, ${ }^{1,5,6,7}$ Adrian Quan, ${ }^{1,6,7}$ K. W. Annie Bang, ${ }^{2,7}$ Guilin Wang, ${ }^{1,6,7}$ Fina Lovren, ${ }^{1,6,7}$ Vivian Vu, ${ }^{12}$ \\ Jack J. Haitsma, ${ }^{3,7}$ Paul E. Szmitko, ${ }^{8}$ Mohammed Al-Omran, ${ }^{9}$ Chao-Hung Wang, ${ }^{10}$ Milan Gupta, ${ }^{1,5,11}$ \\ Mark D. Peterson, ${ }^{1,6,7}$ Haibo Zhang, ${ }^{3,4,7}$ Lawrence Chan, ${ }^{13}$ John Freedman, ${ }^{2,7}$ Gary Sweeney, ${ }^{12}$ \\ and Subodh Verma ${ }^{1,5,6,7}$ \\ Divisions of ${ }^{1}$ Cardiovascular and Thoracic Surgery, ${ }^{2}$ Transfusion Medicine, and ${ }^{3}$ Critical Care, ${ }^{4}$ Department of Anaesthesia, \\ ${ }^{5}$ Cardiometabolic Risk Initiative, ${ }^{6}$ Terrence Donnelly Research Laboratories, ${ }^{7}$ Keenan Research Centre, Li Ka Shing \\ Knowledge Institute, St. Michael's Hospital; ${ }^{8}$ Department of General Internal Medicine, University of Toronto, Toronto, \\ Ontario, Canada; ${ }^{9}$ Division of Vascular Surgery, College of Medicine and King Khalid University Hospital, King Saud \\ University-Li Ka Shing Collaborative Research Program, Riyadh, Kingdom of Saudi Arabia; ${ }^{10}$ Division of Cardiology, \\ Department of Internal Medicine, Chang Gung Memorial Hospital, Keelung, Taiwan; ${ }^{11}$ Division of Cardiology, William Osler \\ Health Centre, McMaster University, Hamilton; ${ }^{12}$ Department of Biology, York University, Toronto, Ontario, Canada; \\ and ${ }^{13}$ Departments of Molecular and Cellular Biology and Medicine, Baylor College of Medicine, Houston, Texas
}

Submitted 21 April 2008; accepted in final form 9 July 2008

Teoh H, Quan A, Bang KW, Wang G, Lovren F, Vu V, Haitsma JJ, Szmitko PE, Al-Omran M, Wang C-H, Gupta M, Peterson MD, Zhang H, Chan L, Freedman J, Sweeney G, Verma S. Adiponectin deficiency promotes endothelial activation and profoundly exacerbates sepsis-related mortality. Am J Physiol Endocrinol Metab 295: E658-E664, 2008. First published July 15, 2008; doi:10.1152/ajpendo.90384.2008.-Sepsis is a multifactorial, and often fatal, disorder typically characterized by widespread inflammation and immune activation with resultant endothelial activation. In the present study, we postulated that the adipokine adiponectin serves as a critical modulator of survival and endothelial activation in sepsis. To this aim, we evaluated both loss-of-function (adiponectin genedeficient mice) and subsequent gain-of-function (recombinant adiponectin reconstitution) strategies in two well-established inflammatory models, cecal ligation perforation (CLP) and thioglyocollateinduced peritonitis. Adipoq ${ }^{-/-}$mice, subjected to CLP, exhibited a profound $(\sim 8$-fold) reduction in survival compared with their wildtype Adipo ${ }^{+1+}$ littermates after 48 h. Furthermore, compared with wild-type controls, thioglycollate challenge resulted in a markedly greater influx of peritoneal neutrophils in Adipo $^{-1-}$ mice accompanied by an excess production of key chemoattractant cytokines (IL$12 \mathrm{p} 70$, TNF $\alpha, \mathrm{MCP}-1$, and IL-6) and upregulation of aortic endothelial adhesion molecule VCAM-1 and ICAM-1 expressions. Importantly, all of these effects were blunted by recombinant total adiponectin administration given 3 days prior to thioglycollate challenge. The protective effects of adiponectin were ascribed largely to higher-order adiponectin oligomers, since administration of recombinant C39A trimeric adiponectin did not attenuate endothelial adhesion molecule expression in thioglycollate-challenged Adipoq ${ }^{-/-}$mice. These data suggest a critical role of adiponectin as a modulator of survival and endothelial inflammation in experimental sepsis and a potential mechanistic link between adiposity and increased sepsis.

adipokine; neutrophil recruitment; cytokines

DESPITE EXTENSIVE RESEARCH, sepsis remains the leading cause of death in critically ill patients worldwide (6). Although several pathophysiological pathways have been described, the com-

Address for reprint requests and other correspondence: S. Verma, Div. of Cardiovascular and Thoracic Surgery, Suite 8-003F, Bond Wing, St. Michael's Hospital, 30 Bond St., Toronto, ON, Canada M5B 1W8 (e-mail: subodh.verma @ sympatico.ca). mon mechanistic theme involves a profound imbalance between inflammatory and immune responses that culminate into widespread endothelial activation and vascular dysfunction.

Among the numerous risk factors that predispose to sepsisrelated complications, obesity and diabetes have been suggested to be prominent risk factors for case fatality in bacteremic patients $(4,38,43)$. Although the impact of adiposity toward sepsisrelated complications is likely multifactorial in nature, one suggestion is that this may be related to alterations in adipocyte biology and adipokine profiles (38).

The adipose tissue produces various bioactive adipokines, of which adiponectin is the most abundant, accounting for $0.01 \%$ of the total plasma proteins (1). Numerous studies indicate that reduced adiponectin levels are observed in patients with obesity and diabetes and may link adiposity to adverse cardiovascular outcomes in these patients $(1,8,9,14,17,21)$. From a biological standpoint, adiponectin has been demonstrated to exert profound anti-inflammatory and antiatherosclerotic effects, in part via diminishing endothelial activation and leukocyteendothelial interaction $(28,29)$.

Given the important anti-inflammatory and vasculoprotective effects of adiponectin, it is plausible that adiponectin deficiency may predispose to sepsis-related complications in states of obesity, diabetes, and insulin resistance.

To gain fundamental insight into this question, we evaluated, in adiponectin-deficient mice, survival following cecal ligation and perforation (an experimental sepsis surrogate) and endothelial activation in a thioglycollate-induced inflammation model. Furthermore, we evaluated whether this phenotype can be rescued by recombinant adiponectin administration and the potential contribution of adiponectin oligomers toward these effects.

\section{MATERIALS AND METHODS}

Animals. All procedures adhered to the guidelines of the Canadian Council on Animal Care and were approved by the Institutional

\footnotetext{
The costs of publication of this article were defrayed in part by the payment of page charges. The article must therefore be hereby marked "advertisement" in accordance with 18 U.S.C. Section 1734 solely to indicate this fact.
} 


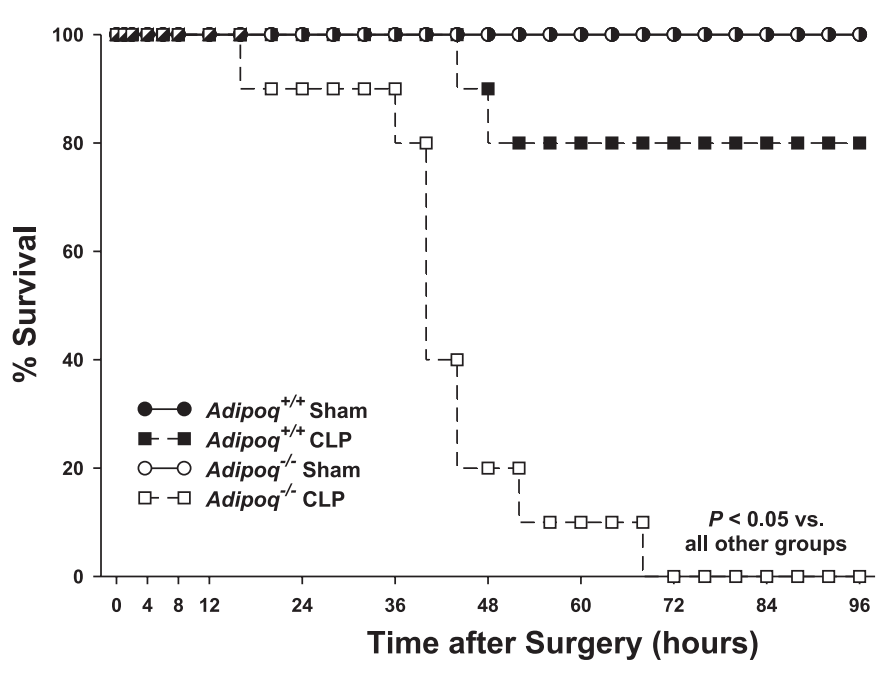

Fig. 1. Survival curves for Adipoq ${ }^{-/-}$and Adipoq ${ }^{+/+}$mice following cecal ligation perforation (CLP) and sham procedures. Naïve mice, randomly assigned to undergo either a CLP procedure or a sham operation, were monitored for $\leq 96$ h postsurgery; $n=8$ for sham groups, $n=10$ for CLP groups.

Animal Care Committee at St. Michael's Hospital. Studies were performed on male $(8-10 \mathrm{wk})$ adiponectin knockout $\left(\right.$ Adipoq $\left.^{-/-}\right)$ mice, with their wild-type $\left(\right.$ Adipo $\left.^{+/+}\right)$littermates acting as controls (18). Genotyping was performed by routine PCR on ear DNA.

Cecal ligation and perforation model. Anesthetized $(10 \mathrm{mg} / \mathrm{kg}$ xylazine-150 mg/kg ketamine ip) mice underwent $<1 \mathrm{~cm}$ midline laparotomies. Cecums were ligated $\sim 0.5 \mathrm{~cm}$ distal to the ileocecal valves, and each cecal stump was subjected to a single "through-andthrough" puncture (18-gauge needle). The cecums were returned to the peritoneal cavities and the incisions closed with dual layers of running sutures. The ligation and perforation steps were omitted in the otherwise identically sham-operated group. All mice received fluid resuscitation $(1 \mathrm{ml}$ of saline $\mathrm{sc})$ and analgesic support $(0.03 \mathrm{mg} / \mathrm{kg}$ buprenorphine sc bid) postoperatively. Animals were monitored for $\leq 96 \mathrm{~h}$ postsurgery.

Peritonitis model. Conscious mice were bled from the right saphenous vein and anesthetized with $10 \mathrm{mg} / \mathrm{kg}$ xylazine- $200 \mathrm{mg} / \mathrm{kg}$ ketamine (ip). Osmotic pumps (Alzet) implanted in the subscapular pockets delivered saline $(1 \mu \mathrm{l} / \mathrm{h})$ or mouse recombinant adiponectin (50 $\mu \mathrm{g}$ /day total or C39A trimeric adiponectin; Biovendor). Both forms of recombinant adiponectin contained the same levels of endotoxin $(<0.1 \mathrm{EU} / \mu \mathrm{g})$, as determined by a Limulus amebocyte lysate kit (Wako) and confirmed by SDS-PAGE gel resolution. Blood was collected from the left saphenous vein $30 \mathrm{~h}$ after surgery. Three days postimplant, mice were injected (ip) with either $1 \mathrm{ml}$ of $3 \%$ thioglycollate (Difco) or an equivolume of saline $4 \mathrm{~h}$ prior to being anesthetized with the aforementioned xylazine-ketamine cocktail. Each peritoneal cavity was lavaged with $4 \mathrm{ml}$ of ice-cold modified PBS (containing 1\% BSA and $5 \mathrm{mM}$ EDTA), and whole blood samples were obtained via cardiac puncture. PBS-flushed aortas were fixed under pressure with $2 \%$ paraformaldehyde, embedded in optimal cutting tissue, and stored at $-80^{\circ} \mathrm{C}$.

Whole blood samples were divided into two; one half was allowed to clot at room temperature for $30 \mathrm{~min}$ to isolate sera and the other was collected into EDTA. Serum adiponectin was assessed with a commercially available ELISA kit (Biovendor) and Western blotting (40). Cytokines were measured in frozen serum samples using the BD Cytometric Bead Array Mouse Inflammation Kit (BD Biosciences) for flow cytometry.

Leukocyte subpopulations in peripheral whole blood or peritoneal lavage were identified by flow cytometric immunophenotyping methods. Aliquots of whole blood or peritoneal lavage were preincubated with mouse BD Fc Block (rat anti-mouse CD16/CD32), and antibody cocktails were added: PerCP-Cy5.5-conjugated anti-CD45 (clone 30F11), FITC-conjugated anti-Gr-1 (clone RB6-8C5), and PE-conjugated anti-CD11b (clone M1/70) to identify myeloid (including neutrophil) subpopulations and PerCP-Cy5.5-conjugated anti-CD45 (clone 30-F11), FITC-conjugated anti-CD3 (clone 17A2), and PEconjugated anti-CD19 (clone 1D3) to identify lymphoid subpopulations. Following incubation with the antibody cocktails, erythrocytes in the whole blood samples were lysed using FACSLyse reagent while an aliquot of CountBright absolute counting beads (Molecular Probes) was added to the peritoneal lavage samples to enumerate absolute neutrophil count. Data for the latter were calculated against the retrieved lavage volumes, which were in the range of 3.1-4.5 ml. The whole blood immunophenotyping method yielded CD45 by side scatter profiles similar to those of normal human peripheral leukocytes (Supplemental Fig. 1A; Supplemental Material for this article is available at the AJP-Endocrinology and Metabolism web site). In every sample, parallel analyses were performed with the corresponding fluorochrome-conjugated isotype controls (Supplemental Fig. 1B). Data were acquired on a FACSCalibur (BD Biosciences) flow cytometer equipped with a 15-mW 488-nm argon gas laser. Unless otherwise stated, all reagents and antibodies were from BD Biosciences.

Transverse aortic cryosections $(5 \mu \mathrm{m})$ were blocked with normal donkey serum (Santa Cruz) and stained with either goat anti-mouse vascular cell adhesion molecule-1 (VCAM-1) or intercellular adhesion molecule-1 (ICAM-1) antibodies (R\&D). Negative controls were performed with the appropriate normal IgG. Fluorescent detection was achieved with a Molecular Probes Alexa Fluor 488 donkey anti-goat antibody. Micrographs, digitally captured under uniform microscope and image capture settings, were processed with Adobe Photoshop to determine the number of pixels fluorescing above an empirically determined threshold. Two blinded observers each independently analyzed the signal strength in two sections from two distinct segments of each aorta using the ImageJ software (http://rsb.info.nih.gov/ij/). Data from each animal in each group were averaged to obtain a single value for statistical analysis.

Statistical analyses. Results are expressed as means \pm SE for number of animals, with $P<0.05$ representing statistical significance. Means were compared using Student's $t$-test.

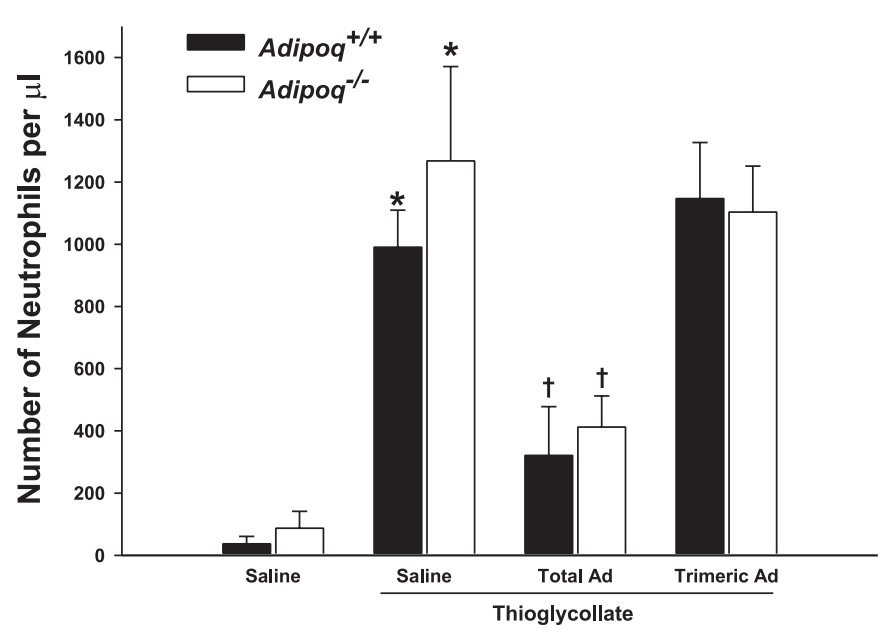

Fig. 2. Adipo ${ }^{-/-}$mice initiate an inflammatory response to thioglycollate that is partially reversed by recombinant mouse total, but not C39A trimeric, adiponectin. Mice were administered saline or $50 \mu \mathrm{g} /$ day sc recombinant mouse adiponectin (Ad) for 3 days. Four hours after challenge with either $1 \mathrm{ml}$ ip of 3\% thioglycollate or saline, neutrophil recruitment was determined in peritoneal lavage samples by flow cytometry; $n=6-8$. $* P<0.05$ vs. corresponding non-thioglycollate-challenged group; $\dagger P<0.05$ vs. corresponding saline-treated group. 


\section{RESULTS}

Survival after cecal ligation and perforation is profoundly impaired in adiponectin-deficient mice. Adipoq ${ }^{-1-}$ mice and Adipo $^{+/+}$littermate controls were subjected to cecal ligation perforation (CLP)-induced sepsis. Sham-operated animals served as controls. Figure 1 illustrates the survival curves for mice in which CLP was performed and clearly demonstrates the profound reduction in survival of Adipoq ${ }^{-/-}$mice. Eight of the 10 Adipoq $^{+/+}$mice that underwent the CLP procedure were still alive $96 \mathrm{~h}$ postsurgery. Strikingly, none of the Adipo $^{-/-}$mice that had the CLP procedure performed $(n=$ 10) survived beyond the 72-h observation window. Median survival time post-CLP was $42 \mathrm{~h}$ in Adipoq $^{-/-}$mice vs. $96 \mathrm{~h}$ in Adipoq $^{+/+}$mice $(P<0.05)$.

Peritonitis-associated neutrophil recruitment is exaggerated in adiponectin-deficient mice. To study the functional role of adiponectin in inflammation, we performed short-term thioglycollate-induced peritonitis experiments to elicit the endogenous inflammatory program. Acute $(4 \mathrm{~h})$ thioglycollate challenge led to intense recruitment of neutrophils into the abdominal cavity of Adipoq ${ }^{+/+}$wild-type mice (Fig. 2). Strikingly, this response was markedly exaggerated in Adipoq ${ }^{-/-}$mice, as evidenced by higher neutrophil counts in the peritoneal lavage fluid (Fig. 2). The relative distributions of the individual leukocyte subpopulations were similar between the groups (Fig. 3), confirming that the enhanced thioglycollate-evoked responses in Adipoq ${ }^{-/-}$mice could not be accounted for by altered systemic neutrophil viability or a change in the relative composition of the leukocyte populations (monocytes, lymphocytes, and granulocytes).

Adiponectin reconstitution experiments were performed by administering recombinant mouse adiponectin via osmotic minipumps 3 days prior to thioglycollate challenge. Adenoviral adiponectin delivery is a commonly utilized knockback strategy $(13,22,23,25,33,34)$ but results in exclusive hepatic expression of the gene $(23,42)$ with limited evidence to date

\section{Adipoq $^{+/+}$}

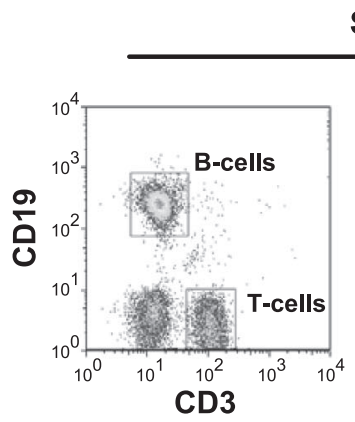

Saline

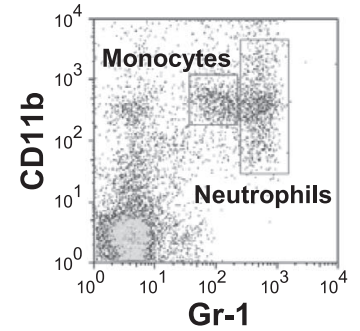

Adipoq $^{-/-}$

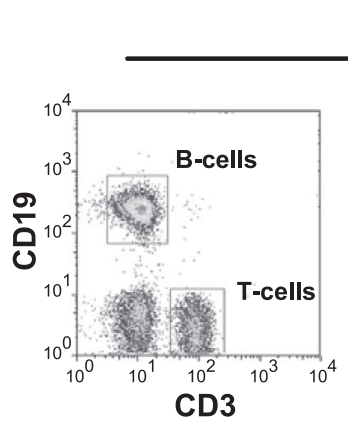

Saline

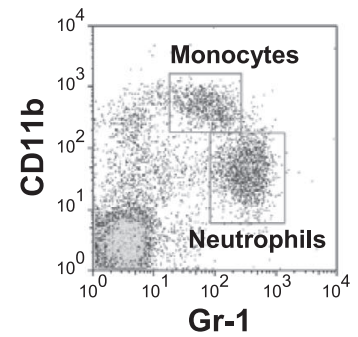

Thioglycollate
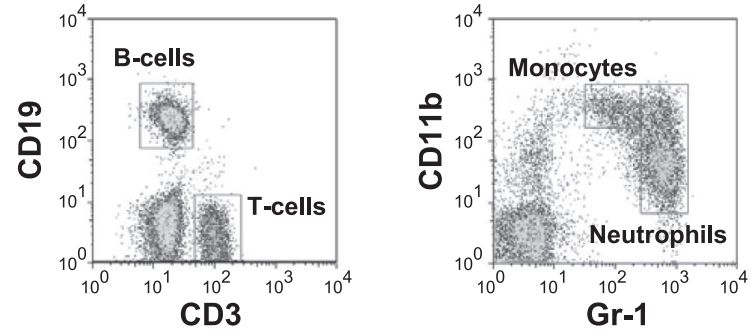

hioglycollate
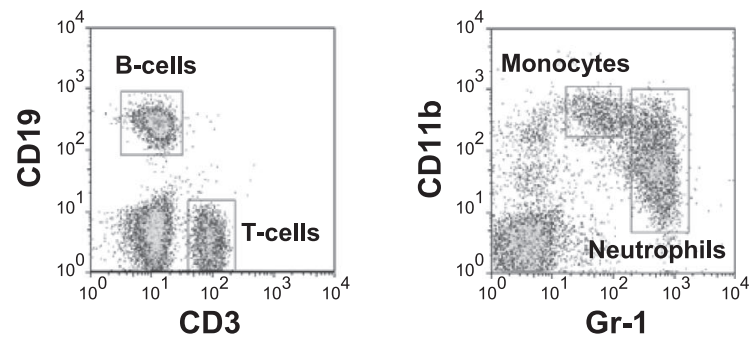

\begin{tabular}{cccccc}
\hline Genotype & Treatment & $\begin{array}{c}\text { T cells } \\
\text { CD3 }^{+}\end{array}$ & $\begin{array}{c}\text { B cells } \\
\text { CD19 }^{+}\end{array}$ & $\begin{array}{c}\text { Monocytes } \\
\text { Gr-1/.CD11b }^{+}\end{array}$ & $\begin{array}{c}\text { Neutrophils } \\
\text { Gr-1 }_{\text {hi CD11b }}{ }^{+}\end{array}$ \\
\hline \multirow{2}{*}{ Adipoq $^{+/+}$} & Saline & $27.7 \pm 1.9 \%$ & $45.3 \pm 2.8 \%$ & $3.9 \pm 0.8 \%$ & $13.5 \pm 3.2 \%$ \\
& Thioglycollate & $20.3 \pm 1.5 \%$ & $24.8 \pm 0.7 \%$ & $7.5 \pm 1.0 \%$ & $40.0 \pm 0.8 \%$ \\
Adipoq $^{-/-}$ & Saline & $24.3 \pm 1.7 \%$ & $47.1 \pm 3.8 \%$ & $5.4 \pm 0.7 \%$ & $14.3 \pm 2.8 \%$ \\
& Thioglycollate & $21.2 \pm 1.4 \%$ & $26.4 \pm 1.0 \%$ & $8.6 \pm 0.8 \%$ & $37.2 \pm 1.5 \%$ \\
\hline
\end{tabular}

Fig. 3. Leukocyte differential profiles. Representative dot plots demonstrating $\mathrm{CD}_{4} 5^{+}$leukocyte subpopulations in the peripheral blood of Adipoq ${ }^{-1-}$ and Adipo $q^{+1+}$ mice administered saline or thioglycollate. Corresponding subpopulation percentages as a proportion of all CD45 $5^{+}$leukocytes are shown in the table; $n=5-7$ for each group. 
demonstrating that the resulting proteins undergo the same posttranslational modification as native adiponectin $(3,32,42)$. To circumvent these issues, we opted to continually infuse into our mice mammalian cell (HEK-293)-derived recombinant mouse adiponectin. Levels of total adiponectin in Adipoq ${ }^{+/+}$ mice administered saline, recombinant total, or C39A trimeric adiponectin were similar $(11.93 \pm 0.54,11.83 \pm 0.91$, and $11.45 \pm 1.08 \mu \mathrm{g} / \mathrm{ml}$, respectively). Total adiponectin was virtually undetectable in the sera of Adipoq ${ }^{-/-}$mice administered saline $(0.01 \pm 0.01 \mu \mathrm{g} / \mathrm{ml})$. Delivery of recombinant total adiponectin resulted in a significant increase in serum adiponectin concentrations $(4.85 \pm 0.15 \mu \mathrm{g} / \mathrm{ml}, P=0.02)$, with elevations observed in all three adiponectin isoforms (Supplemental Fig. 2). Reconstitution with recombinant C39A trimeric adiponectin raised serum adiponectin concentrations to $0.29 \pm$ $0.03 \mu \mathrm{g} / \mathrm{ml}(P<0.01)$. Importantly, administration of recombinant total adiponectin prior to thioglycollate challenge rescued the inflammation defect, as evidenced by similar peritoneal leukocyte counts in non-thioglycollate-challenged Adipo $q^{+/+}$wild-type and Adipoq ${ }^{-1-}$ mice (Fig. 2). In contrast, recombinant C39A trimeric adiponectin had no effect on thioglycollate-induced neutrophil recruitment (Fig. 2).

Increased cytokine production in adiponectin-deficient mice subjected to peritonitis. We next evaluated the impact of peritonitis on systemic cytokine elaboration, an important endogenous response to inflammation. Figure 4 illustrates the serum levels of key chemoattractant cytokines IL-12p70, $\mathrm{TNF} \alpha$, monocyte chemoattractant protein-1, and IL-6 in Adipoq $^{-/-}$and Adipoq ${ }^{+/+}$wild-type control mice. Thioglycollate challenge led to a significant increase in the serum levels of these cytokines, and this effect was significantly greater in Adipo $^{-/-}$mice vs. Adipoq ${ }^{+/+}$mice. Importantly, recombinant total adiponectin administration exhibited anti-inflamma- tory effects, evidenced by a marked reduction in the levels of these cytokines in Adipoq ${ }^{-/-}$mice and Adipoq ${ }^{+/+}$mice subjected to thioglycollate administration (Fig. 4). Serum IL-10 levels did not vary statistically between the individual groups (data not shown).

Adiponectin deficiency promotes heightened endothelial adhesion molecule expression in response to peritonitis. Leukocyte recruitment to inflamed tissues is the result of a complex cascade of events that promote leukocyte tethering to an activated endothelium. Therefore, we studied the influence of adiponectin on endothelial cell adhesion molecule expression. To this end, we analyzed the expression of VCAM-1 and ICAM-1 in aortic sections from Adipoq ${ }^{-/-}$and Adipoq ${ }^{+/+}$ mice subjected to thioglycollate administration (Figs. 5 and 6). Endothelial expression of both VCAM-1 and ICAM-1 was markedly increased in aortic sections from Adipoq ${ }^{-/-}$mice subjected to thioglycollate treatment (Figs. 5 and 6). Pretreatment with recombinant total adiponectin significantly inhibited the increase in cellular adhesion molecule expression.

Total adiponectin circulates in the serum as a trimeric and a larger multimeric structure of high molecular weight (HMW) $(30,41)$. Recent evidence suggests that the HMW (vs. trimeric) isoform of adiponectin is more functionally active $(2,10)$. To further gauge the importance of adiponectin oligomeric isoforms toward inflammation, we compared the impact of recombinant C39A trimeric adiponectin administration (vs. total adiponectin) on endothelial expression of VCAM-1 and ICAM-1 in response to thioglycollate administration. As shown in Figs. 5 and 6, recombinant C39A trimeric adiponectin administration did not attenuate adhesion molecule expression in Adipoq $^{-/-}$mice compared with administration of total
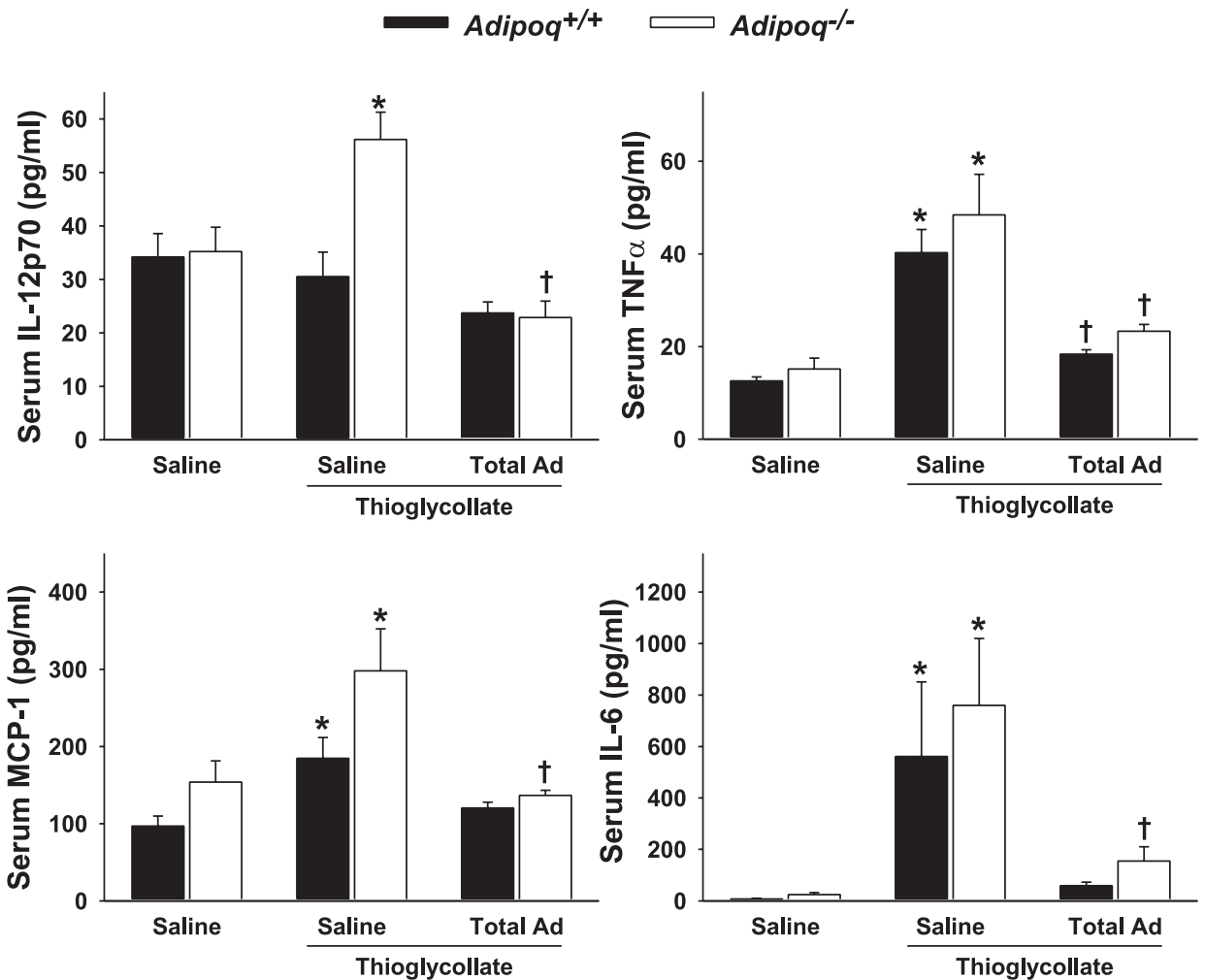

Fig. 4. Thioglycollate stimulation evokes greater cytokine releases in Adipoq ${ }^{-/}$than in Adipoq ${ }^{++}$mice, and these are suppressed by recombinant mouse total adiponectin (Total Ad). Mice were administered saline or $50 \mu \mathrm{g} /$ day sc recombinant mouse total adiponectin for 3 days. Four hours after challenge with 1 $\mathrm{ml}$ ip of 3\% thioglycollate or saline, peripheral whole blood samples were collected for serum cytokine profiling; $n=5-7$. $* P<0.05$ vs. corresponding non-thioglycollate-challenged group; $\dagger P<0.05$ vs. corresponding salinetreated group.

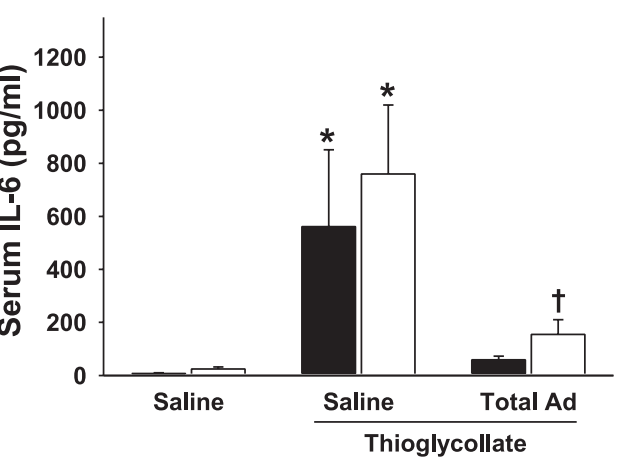

AJP-Endocrinol Metab $•$ VOL $295 \bullet$ SEPTEMBER $2008 \cdot$ www.ajpendo.org 

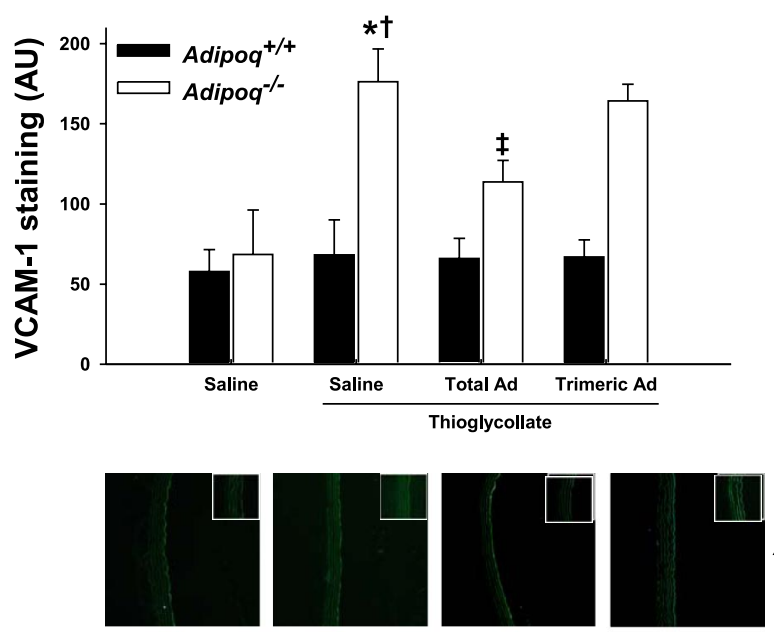

Adipoq $^{+/+}$
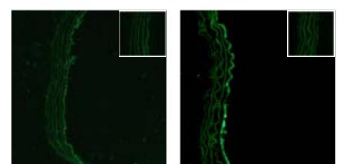

Saline

Saline

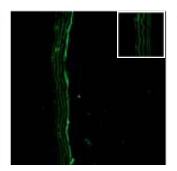

Total Ad Thioglycollate

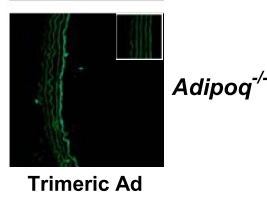

Fig. 5. Thioglycollate-induced aortic vascular cell adhesion molecule-1 (VCAM-1) staining is greater in Adipoq ${ }^{-/-}$mice than in Adipoq ${ }^{+/+}$littermates, an effect that is partially reversed by recombinant mouse total, but not C39A trimeric, Ad. Mice were administered saline or $50 \mu \mathrm{g} / \mathrm{day} \mathrm{sc}$ recombinant mouse adiponectin for 3 days. Four hours after challenge with $1 \mathrm{ml}$ ip of $3 \%$ thioglycollate or saline, mice were killed and paraformaldehyde-fixed aortic segments harvested for cryosectioning. Aortic sections were probed with a VCAM-1-specific antibody, and staining was fluorescently quantified; $n=$ 4-5. $* P<0.05$ vs. corresponding non-thioglycollate-challenged group; $\uparrow P<$ 0.05 vs. corresponding Adipoq ${ }^{+1+}$ group; $\ddagger P<0.05$ vs. corresponding saline-treated group. Micrographs were taken at $\times 10$ magnification, with negative controls shown in the insets.

adiponectin, suggesting that higher-order adiponectin oligomers are likely anti-inflammatory in this model.

\section{DISCUSSION}

Our observations add to the growing list of anti-inflammatory, immunomodulatory, and vasculoprotective effects of adiponectin. Numerous clinical studies indicate the relationship between low adiponectin levels and high levels of C-reactive protein $(15,21,27,31)$, an emerging biomarker and prognosticator of cardiometabolic risk (39). Circulating adiponectin levels are diminished in states of obesity, diabetes, and insulin resistance and are inversely correlated with other well-established cardiovascular risk factors such as hypertension and elevated cholesterol. Furthermore, low levels of adiponectin have been shown to be an independent risk factor for the development of diabetes, hypertension, and coronary artery disease $(1,8,11,16,26,27)$. Several studies suggest that the cardiometabolic benefits of adiponectin may be driven largely through improvements in vascular homeostasis, particularly through improving endothelial function. Previous studies have demonstrated impaired endothelial function in adiponectindeficient mice (28) and in diabetic and nondiabetic patients $(28,35)$. Adiponectin has also been demonstrated to limit aberrant leukocyte endothelial interaction within the microcirculation in part through augmenting nitric oxide bioavailability (29). Adiponectin exerts potent anti-inflammatory effects, as documented by a reduction in $\mathrm{TNF} \alpha$ in plasma, adipose tissue, vasculature, heart, and liver (19, 25, 33, 37, 44). Adiponectin has been demonstrated to afford unique protection against myocardial ischemia and reperfusion injury in part through cyclooxygenase-2 and AMP kinase-dependent mechanisms (33).

In the present study, we hypothesized that adiponectin, one of the main proteins produced by the adipose tissue, plays an important role to limit endothelial activation and inflammation in experimental sepsis. Our data support this contention by demonstrating that adiponectin-deficient mice exhibit profound reduction in survival following CLP, a well-established model that mimics the pathophysiology of human sepsis. This finding is consistent with the short-term observations of Tsuchihashi et al. (36), who reported that plasma adiponectin levels were inversely correlated with those of endotoxin and TNF $\alpha$ in naïve rats $24 \mathrm{~h}$ after CLP. Furthermore, we found that adiponectin deficiency elicits a heightened inflammatory response to thioglycollate-induced peritonitis, as evidenced by a greater recruitment of neutrophils in the peritoneal cavity, exaggerated cytokine and chemokine production, and heightened endothelial cell adhesion molecule, VCAM-1, and ICAM-1 expression in Adipoq $^{-1-}$ vs. Adipoq ${ }^{+/+}$mice.

To the best of our knowledge, this is the first report to distinguish neutrophils as targets of adiponectin and extends recent demonstrations of the unique effects of adiponectin to modulate immune system function. Takemura et al. (34) demonstrated the ability of adiponectin to opsonize apoptotic
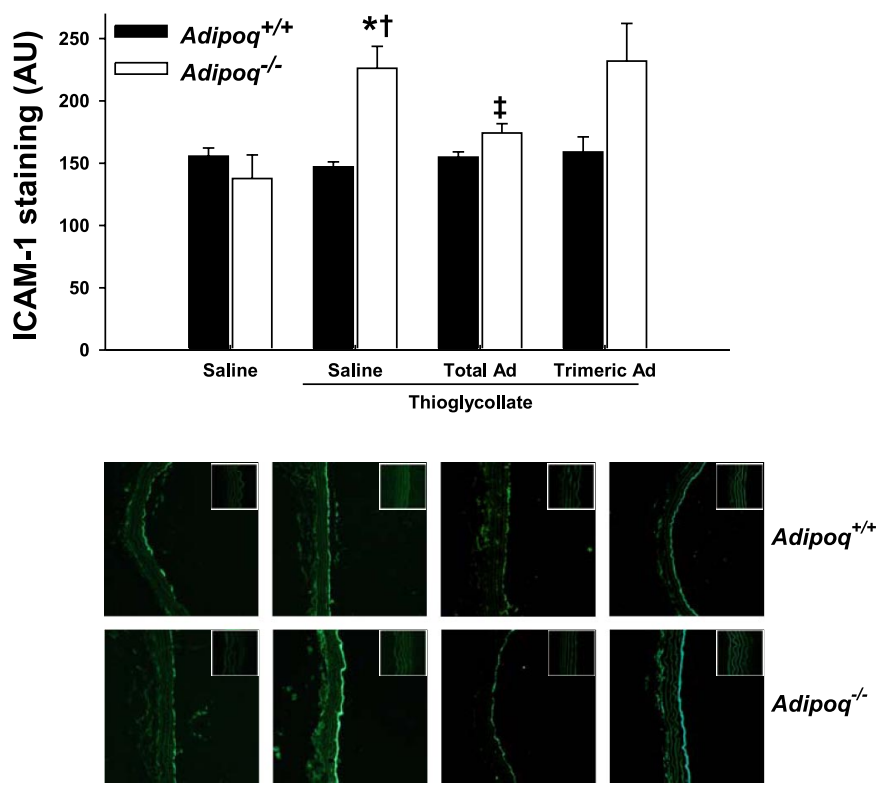

Saline

Saline

Total Ad

Trimeric Ad

Thioglycollate

Fig. 6. Thioglycollate-induced aortic intercellular adhesion molecule-1 (ICAM-1) staining is greater in Adipoq ${ }^{-/-}$mice than in Adipoq ${ }^{+/+}$littermates, an effect that is partially reversed by recombinant mouse total, but not C39A trimeric, Ad. Mice were administered saline or $50 \mu \mathrm{g} /$ day sc recombinant mouse adiponectin for 3 days. Four hours after challenge with $1 \mathrm{ml}$ ip of $3 \%$ thioglycollate or saline, mice were killed and paraformaldehyde-fixed aortic segments harvested for cryosectioning. Aortic sections were probed with an ICAM-1-specific antibody, and staining was fluorescently quantified; $n=4-5$. $* P<0.05$ vs. corresponding non-thioglycollate-challenged group; $\uparrow P<0.05$ vs. corresponding Adipoq ${ }^{+1+}$ group; $\ddagger P<0.05$ vs. corresponding salinetreated group. Micrographs were taken at $\times 10$ magnification, with negative controls shown in the insets. 
cells and promote macrophage phagocytosis of cell corpses. Those authors suggested that adiponectin may attenuate systemic inflammation by promoting the clearance of early apoptotic cells by macrophages. Furthermore, adiponectin may serve as a regulator of T-lymphocyte-active CXCR3 chemokine ligands and T-lymphocyte migration, acting as an endogenous inhibitor of adaptive immunity (24), although equivocal data exist on the role of adiponectin on endotoxin-induced injury. Collectively, these results suggest that the anti-inflammatory actions of adiponectin are mediated at least in part via its effects on different leukocyte subtypes.

The primary adiponectin receptors, AdipoR1 and AdipoR2 (45), trigger downstream activation of the AMP kinase, the peroxisome proliferator activated receptor- $\alpha$, and the p38 mitogen-activated kinase signaling pathways [reviewed by Kadowaki and Yamauchi (12)]. Macrophages express both AdipoR1 and AdipoR2, and notably, shifts in receptor dominance from AdipoR1 to AdipoR2 accompany monocytic differentiation into mature macrophages $(5,20)$. Interestingly, however, part of the macrophage-associated anti-inflammatory actions of adiponectin does not involve activation of intracellular signaling and instead revolves around calreticulin on the macrophage cell surface and the recognition motif apoptotic cell-associated molecular patterns on the dead cell surface (34). That adiponectin concurrently elicits non-receptor-mediated events is unsurprising in view of the typically high circulating levels of adiponectin. Although adiponectin receptors have not been reported in neutrophils, the current findings indicate that the possibility cannot be discounted. Whether or not the protective effects of adiponectin we observed in our inflammatory models were receptor dependent or receptor independent was beyond the scope of the current study but clearly merits further investigation.

In our hands, gain-of-function approaches via recombinant total adiponectin administration rescued the inflammatory phenotype, with the suggestion that this may be mediated largely through the HMW isoform, since administration of C39A trimeric adiponectin (vs. total adiponectin) did not attenuate thioglyocollate-induced peritoneal neutrophil recruitment or VCAM-1 and ICAM-1 expressions. This observation is in line with and lends credence to the literature suggesting that the HMW (vs. trimeric) isoform of adiponectin is the more functionally active class of the protein and, as such, may be the oligomer of potential importance as a therapeutic target $(2,10)$. Recent in vitro reports indicate that physiological concentrations of adiponectin suppress endothelial cell and hepatocyte C-reactive protein synthesis and secretion (7). Accordingly, our reconstitution studies suggest the possibility that the higher plasma concentrations of adiponectin present in nonobese individuals may effectively reduce the effects of proinflammatory chemokines.

To the best of our knowledge, this study is the first to demonstrate a critical role of adiponectin in sepsis-related inflammation and survival, likely through a multifactorial antiinflammatory mechanism that serves to limit leukocyte infiltration, chemotaxis, and endothelial activation. We suggest that clinical conditions associated with hypoadiponectinemia, such as obesity, diabetes, and insulin resistance, may predispose to sepsis-related complications through altered adipokine homeostasis.

\section{GRANTS}

This work was supported in part by grants from the Heart and Stroke Foundation (Grant Nos. NA 6115 and T6213) to S. Verma and G. Sweeney, the Canadian Institutes of Health Research (Grant No. 77711) to S. Verma, and the National Heart, Lung, and Blood Institute (Grant No. HL-51586) to L. Chan. V. Vu is supported by the Canadian Diabetes Association, J. J. Haitsma by the W. Garfield Weston Foundation, and P. E. Szmitko by the Physicians Services Incorporated Foundation. S. Verma holds the Canada Research Chair in Atherosclerosis.

\section{REFERENCES}

1. Arita Y, Kihara S, Ouchi N, Takahashi M, Maeda K, Miyagawa J, Hotta K, Shimomura I, Nakamura T, Miyaoka K, Kuriyama H, Nishida M, Yamashita S, Okubo K, Matsubara K, Muraguchi M, Ohmoto Y, Funahashi T, Matsuzawa Y. Paradoxical decrease of an adipose-specific protein, adiponectin, in obesity. Biochem Biophys Res Commun 257: 79-83, 1999.

2. Aso Y, Yamamoto R, Wakabayashi S, Uchida T, Takayanagi K, Takebayashi K, Okuno T, Inoue T, Node K, Tobe T, Inukai T, Nakano Y. Comparison of serum high-molecular weight (HMW) adiponectin with total adiponectin concentrations in type 2 diabetic patients with coronary artery disease using a novel enzyme-linked immunosorbent assay to detect HMW adiponectin. Diabetes 55: 1954-1960, 2006.

3. Berg AH, Combs TP, Du X, Brownlee M, Scherer PE. The adipocytesecreted protein Acrp30 enhances hepatic insulin action. Nat Med 7: 947-953, 2001.

4. Black PR, Brooks DC, Bessey PQ, Wolfe RR, Wilmore DW. Mechanisms of insulin resistance following injury. Ann Surg 196: 420-435, 1982

5. Chinetti G, Zawadski C, Fruchart JC, Staels B. Expression of adiponectin receptors in human macrophages and regulation by agonists of the nuclear receptors PPARalpha, PPARgamma, and LXR. Biochem Biophys Res Commun 314: 151-158, 2004.

6. Dellinger RP, Levy MM, Carlet JM, Bion J, Parker MM, Jaeschke R, Reinhart K, Angus DC, Brun-Buisson C, Beale R, Calandra T, Dhainaut JF, Gerlach H, Harvey M, Marini JJ, Marshall J, Ranieri M, Ramsay G, Sevransky J, Thompson BT, Townsend S, Vender JS, Zimmerman JL, Vincent JL; International Surviving Sepsis Campaign Guidelines Committee; American Association of Critical-Care Nurses; American College of Chest Physicians; American College of Emergency Physicians; Canadian Critical Care Society; European Society of Clinical Microbiology and Infectious Diseases; European Society of Intensive Care Medicine; European Respiratory Society; International Sepsis Forum; Japanese Association for Acute Medicine; Japanese Society of Intensive Care Medicine; Society of Critical Care Medicine; Society of Hospital Medicine; Surgical Infection Society; World Federation of Societies of Intensive and Critical Care Medicine. Surviving Sepsis Campaign: international guidelines for management of severe sepsis and septic shock: 2008. Crit Care Med 36: 296-327, 2008.

7. Devaraj S, Torok N, Dasu MR, Samols D, Jialal I. Adiponectin decreases C-reactive protein synthesis and secretion from endothelial cells: evidence for an adipose tissue-vascular loop. Arterioscler Thromb Vasc Biol 28: 1368-1374, 2008.

8. Hotta K, Funahashi T, Arita Y, Takahashi M, Matsuda M, Okamoto Y, Iwahashi H, Kuriyama H, Ouchi N, Maeda K, Nishida M, Kihara S, Sakai N, Nakajima T, Hasegawa K, Muraguchi M, Ohmoto Y, Nakamura T, Yamashita S, Hanafusa T, Matsuzawa Y. Plasma concentrations of a novel, adipose-specific protein, adiponectin, in type 2 diabetic patients. Arterioscler Thromb Vasc Biol 20: 1595-1599, 2000.

9. Hu E, Liang P, Spiegelman BM. AdipoQ is a novel adipose-specific gene dysregulated in obesity. J Biol Chem 271: 10697-10703, 1996.

10. Inoue T, Kotooka N, Morooka T, Komoda H, Uchida T, Aso Y, Inukai T, Okuno T, Node K. High molecular weight adiponectin as a predictor of long-term clinical outcome in patients with coronary artery disease. Am J Cardiol 100: 569-574, 2007.

11. Iwashima Y, Katsuya T, Ishikawa K, Ouchi N, Ohishi M, Sugimoto K, Fu Y, Motone M, Yamamoto K, Matsuo A, Ohashi K, Kihara S, Funahashi T, Rakugi H, Matsuzawa Y, Ogihara T. Hypoadiponectine$\mathrm{mia}$ is an independent risk factor for hypertension. Hypertension 43: 1318-1323, 2004.

12. Kadowaki T, Yamauchi T. Adiponectin and adiponectin receptors. Endocr Rev 26: 439-451, 2005. 
13. Kato H, Kashiwagi H, Shiraga M, Tadokoro S, Kamae T, Ujiie H, Honda S, Miyata S, Ijiri Y, Yamamoto J, Maeda N, Funahashi T, Kurata Y, Shimomura I, Tomiyama Y, Kanakura Y. Adiponectin acts as an endogenous antithrombotic factor. Arterioscler Thromb Vasc Biol 26: 224-230, 2006.

14. Kern PA, Di Gregorio GB, Lu T, Rassouli N, Ranganathan G. Adiponectin expression from human adipose tissue: relation to obesity, insulin resistance, and tumor necrosis factor-alpha expression. Diabetes 52: $1779-1785,2003$.

15. Krakoff J, Funahashi T, Stehouwer CD, Schalkwijk CG, Tanaka S, Matsuzawa Y, Kobes S, Tataranni PA, Hanson RL, Knowler WC, Lindsay RS. Inflammatory markers, adiponectin, and risk of type 2 diabetes in the Pima Indian. Diabetes Care 26: 1745-1751, 2003.

16. Kumada M, Kihara S, Sumitsuji S, Kawamoto T, Matsumoto S, Ouchi N, Arita Y, Okamoto Y, Shimomura I, Hiraoka H, Nakamura T, Funahashi T, Matsuzawa Y. Association of hypoadiponectinemia with coronary artery disease in men. Arterioscler Thromb Vasc Biol 23: 85-89, 2003.

17. Li HY, Chiu YF, Hwu CM, Sheu WH, Hung YJ, Fujimoto W, Quertermous T, Curb JD, Tai TY, Chuang LM. The negative correlation between plasma adiponectin and blood pressure depends on obesity: a family-based association study in SAPPHIRe. Am J Hypertens 21: 471-476, 2008.

18. Ma K, Cabrero A, Saha PK, Kojima H, Li L, Chang BH, Paul A, Chan L. Increased beta-oxidation but no insulin resistance or glucose intolerance in mice lacking adiponectin. J Biol Chem 277: 34658-34661, 2002.

19. Maeda N, Shimomura I, Kishida K, Nishizawa H, Matsuda M, Nagaretani H, Furuyama N, Kondo H, Takahashi M, Arita Y, Komuro R, Ouchi N, Kihara S, Tochino Y, Okutomi K, Horie M, Takeda S, Aoyama T, Funahashi T, Matsuzawa Y. Diet-induced insulin resistance in mice lacking adiponectin/ACRP30. Nat Med 8: 731-737, 2002.

20. Maeda N, Takahashi M, Funahashi T, Kihara S, Nishizawa H, Kishida K, Nagaretani H, Matsuda M, Komuro R, Ouchi N, Kuriyama H, Hotta K, Nakamura T, Shimomura I, Matsuzawa Y. PPARgamma ligands increase expression and plasma concentrations of adiponectin, an adipose-derived protein. Diabetes 50: 2094-2099, 2001.

21. Matsubara M, Namioka K, Katayose S. Decreased plasma adiponectin concentrations in women with low-grade C-reactive protein elevation. Eur J Endocrinol 148: 657-662, 2003.

22. Matsuda M, Shimomura I, Sata M, Arita Y, Nishida M, Maeda N, Kumada M, Okamoto Y, Nagaretani H, Nishizawa H, Kishida K, Komuro R, Ouchi N, Kihara S, Nagai R, Funahashi T, Matsuzawa Y. Role of adiponectin in preventing vascular stenosis. The missing link of adipo-vascular axis. J Biol Chem 277: 37487-37491, 2002.

23. Ohashi K, Kihara S, Ouchi N, Kumada M, Fujita K, Hiuge A, Hibuse T, Ryo M, Nishizawa H, Maeda N, Maeda K, Shibata R, Walsh K, Funahashi T, Shimomura I. Adiponectin replenishment ameliorates obesity-related hypertension. Hypertension 47: 1108-1116, 2006.

24. Okamoto Y, Folco EJ, Minami M, Wara AK, Feinberg MW, Sukhova GK, Colvin RA, Kihara S, Funahashi T, Luster AD, Libby P. Adiponectin inhibits the production of CXC receptor 3 chemokine ligands in macrophages and reduces $\mathrm{T}$-lymphocyte recruitment in atherogenesis. Circ Res 102: 218-225, 2008.

25. Okamoto Y, Kihara S, Ouchi N, Nishida M, Arita Y, Kumada M, Ohashi K, Sakai N, Shimomura I, Kobayashi H, Terasaka N, Inaba T, Funahashi T, Matsuzawa Y. Adiponectin reduces atherosclerosis in apolipoprotein E-deficient mice. Circulation 106: 2767-2770, 2002.

26. Ouchi N, Kihara S, Funahashi T, Matsuzawa Y, Walsh K. Obesity, adiponectin and vascular inflammatory disease. Curr Opin Lipidol 14: 561-566, 2003.

27. Ouchi N, Kihara S, Funahashi T, Nakamura T, Nishida M, Kumada M, Okamoto Y, Ohashi K, Nagaretani H, Kishida K, Nishizawa $H$, Maeda N, Kobayashi H, Hiraoka H, Matsuzawa Y. Reciprocal association of C-reactive protein with adiponectin in blood stream and adipose tissue. Circulation 107: 671-674, 2003.

28. Ouchi N, Ohishi M, Kihara S, Funahashi T, Nakamura T, Nagaretani H, Kumada M, Ohashi K, Okamoto Y, Nishizawa H, Kishida K, Maeda N, Nagasawa A, Kobayashi H, Hiraoka H, Komai N, Kaibe M,
Rakugi H, Ogihara T, Matsuzawa Y. Association of hypoadiponectinemia with impaired vasoreactivity. Hypertension 42: 231-234, 2003.

29. Ouedraogo R, Gong Y, Berzins B, Wu X, Mahadev K, Hough K, Chan L, Goldstein BJ, Scalia R. Adiponectin deficiency increases leukocyteendothelium interactions via upregulation of endothelial cell adhesion molecules in vivo. J Clin Invest 117: 1718-1726, 2007.

30. Pajvani UB, Du X, Combs TP, Berg AH, Rajala MW, Schulthess T, Engel J, Brownlee M, Scherer PE. Structure-function studies of the adipocyte-secreted hormone Acrp30/adiponectin. Implications fpr metabolic regulation and bioactivity. J Biol Chem 278: 9073-9085, 2003.

31. Pischon T, Girman CJ, Hotamisligil GS, Rifai N, Hu FB, Rimm EB. Plasma adiponectin levels and risk of myocardial infarction in men. JAMA 291: 1730-1737, 2004.

32. Richards AA, Stephens T, Charlton HK, Jones A, Macdonald GA, Prins JB, Whitehead JP. Adiponectin multimerization is dependent on conserved lysines in the collagenous domain: evidence for regulation of multimerization by alterations in posttranslational modifications. Mol Endocrinol 20: 1673-1687, 2006.

33. Shibata R, Sato K, Pimentel DR, Takemura Y, Kihara S, Ohashi K, Funahashi T, Ouchi N, Walsh K. Adiponectin protects against myocardial ischemia-reperfusion injury through AMPK- and COX-2-dependent mechanisms. Nat Med 11: 1096-1103, 2005.

34. Takemura Y, Ouchi N, Shibata R, Aprahamian T, Kirber MT, Summer RS, Kihara S, Walsh K. Adiponectin modulates inflammatory reactions via calreticulin receptor-dependent clearance of early apoptotic bodies. J Clin Invest 117: 375-386, 2007.

35. Tan KC, Xu A, Chow WS, Lam MC, Ai VH, Tam SC, Lam KS. Hypoadiponectinemia is associated with impaired endothelium-dependent vasodilation. J Clin Endocrinol Metab 89: 765-769, 2004.

36. Tsuchihashi H, Yamamoto H, Maeda K, Ugi S, Mori T, Shimizu T, Endo Y, Hanasawa K, Tani T. Circulating concentrations of adiponectin, an endogenous lipopolysaccharide neutralizing protein, decrease in rats with polymicrobial sepsis. J Surg Res 134: 348-353, 2006.

37. Ujiie H, Oritani K, Kato H, Yokota T, Takahashi I, Maeda T, Masaie H, Ichii M, Kamada Y, Tamura S, Kihara S, Funahashi T, Tomiyama Y, Kanakura Y. Identification of amino-terminal region of adiponectin as a physiologically functional domain. J Cell Biochem 98: 194-207, 2006.

38. Vachharajani V, Vital S. Obesity and sepsis. J Intensive Care Med 21: 287-295, 2006.

39. Verma S, Szmitko PE, Ridker PM. C-reactive protein comes of age. Nat Clin Pract Cardiovasc Med 2: 29-36; quiz 58, 2005.

40. Vu V, Kim W, Fang X, Liu YT, Xu A, Sweeney G. Coculture with primary visceral rat adipocytes from control but not streptozotocin-induced diabetic animals increases glucose uptake in rat skeletal muscle cells: role of adiponectin. Endocrinology 148: 4411-4419, 2007.

41. Waki H, Yamauchi T, Kamon J, Ito Y, Uchida S, Kita S, Hara K, Hada Y, Vasseur F, Froguel P, Kimura S, Nagai R, Kadowaki T. Impaired multimerization of human adiponectin mutants associated with diabetes. Molecular structure and multimer formation of adiponectin. J Biol Chem 278: 40352-40363, 2003.

42. Wang Y, Lam KS, Chan L, Chan KW, Lam JB, Lam MC, Hoo RC, Mak WW, Cooper GJ, Xu A. Post-translational modifications of the four conserved lysine residues within the collagenous domain of adiponectin are required for the formation of its high molecular weight oligomeric complex. J Biol Chem 281: 16391-16400, 2006.

43. White RH, Frayn KN, Little RA, Threlfall CJ, Stoner HB, Irving MH. Hormonal and metabolic responses to glucose infusion in sepsis studied by the hyperglycemic glucose clamp technique. JPEN J Parenter Enteral Nutr 11: 345-353, 1987.

44. Xu A, Wang Y, Keshaw H, Xu LY, Lam KS, Cooper GJ. The fat-derived hormone adiponectin alleviates alcoholic and nonalcoholic fatty liver diseases in mice. J Clin Invest 112: 91-100, 2003.

45. Yamauchi T, Kamon J, Ito Y, Tsuchida A, Yokomizo T, Kita S, Sugiyama T, Miyagishi M, Hara K, Tsunoda M, Murakami K, Ohteki T, Uchida S, Takekawa S, Waki H, Tsuno NH, Shibata Y, Terauchi Y, Froguel P, Tobe K, Koyasu S, Taira K, Kitamura T, Shimizu T, Nagai R, Kadowaki T. Cloning of adiponectin receptors that mediate antidiabetic metabolic effects. Nature 423: 762-769, 2003. 